\title{
The COVID-19 Pandemic - A Global Public Health Crisis: A Brief Overview Regarding Pharmacological Interventions
}

\author{
Mainul Haque 1 (1)
}

${ }^{1}$ Unit of Pharmacology, Faculty of Medicine and Defence Health, Universiti Pertahanan Nasional Malaysia, Kuala Lumpur, Malaysia.

Author to whom correspondence should be addressed: Professor Mainul Haque, Unit of Pharmacology, Faculty of Medicine and Defence Health, Universiti Pertahanan Nasional Malaysia, Kem Sungai Besi, 57000 Kuala Lumpur, Malaysia. Phone: +60 390513400 Ext 2257. E-mail: runurono@gmail.com.

Academic Editor: Alessandro Leite Cavalcanti

Received: 23 June 2020 / Accepted: 07 July 2020 / Published: 13 July 2020

How to cite this article: Haque M. The COVID-19 pandemic - a global public health crisis: a brief overview regarding
pharmacological interventions. Pesqui Bras Odontopediatria Clín Integr. 2020; 20(supp1):e0146.
https://doi.org/10.1590/pboci.2020.137

\begin{abstract}
WHO reported that viral diseases remain as an international public health concern. Quite a lot of viral outbreaks such as the SARS coronavirus from 2002 to 2003, $\mathrm{H} 1 \mathrm{~N} 1$ influenza in 2009, and the MERS syndrome coronavirus in 2012, in the last two decades. The recent outburst of COVID-19 disease has to turn out a global public health catastrophe that has a profound consequence on every aspect of human life. Currently, national governments, international health agencies, UN different bodies are working relentlessly to find the best way to save and mitigate our world from the shattering effects of COVID-19. Simultaneously, all related scientists around the planet determinedly made enormous efforts to find the COVID-19 transmission process, clinicopathological issues, diagnostics tools, and prevention policy planning and pharmacological intervention approaches. There are many problems that are not resolved regarding COVID-19, like the virus-host relations and the development and progression of the pandemic, with precise reference to the times when the current pandemic will reach its ultimate level to produce maximum damage. At this moment in time, yet we do not possess and definite and specific treatment options to fight with the COVID-19 viral infectious diseases. Currently, the majority of the scientist is involved in finding a way through drug repurposing. Up to the present time lot of medicines were identified that possess definite antiviral effects against COVID-19 but need to go a long way with well-designed study to obtain the best possible answer. After that, to this point, supportive and preventive remain as the best weapon.
\end{abstract}

Keywords: Coronavirus Infections; SARS Virus; Disease Outbreaks; Pandemics. 


\section{Introduction}

Microbial diseases (bacteria, viruses, parasites, and fungus) have instigated disaster throughout human history [1]. Emerging and re-emerging microbial diseases along with multiple drug-resistant (MDR), pandrug-resistant (PDR), extensively drug-resistant (XDR) are now taking place at skyrocket high-speed [24]. The World Health Organization (WHO) reported that our planet has feast your eyes on the escalation of quite a lot of infectious disease eruptions and epidemics began by more than twenty infectious agents over the last ten years [5]. These epidemics were often of novel viral origin such as a novel influenza A virus (H1N1) and Middle East respiratory syndrome (MERS) [6-10].

The evolution of coronavirus-associated diseases, Severe Acute Respiratory Syndrome (SARS and MERS) for the last twenty years, imposed comprehensive international challenges regarding the management of these viral diseases and ensured a threat to public health all over the globe $[11,12]$. The SARS-CoV-2 is the causative virus agent for coronavirus disease (COVID-19), the latest version of the $\beta$-coronavirus family, single-stranded RNA, the enveloped virus that is $50-200 \mathrm{~nm}$ in diameter [13-16], after that, the WHO confirmed COVID-19, a public health emergency of global distress on January-30-2020 and a pandemic on March-11-2020 [17-19]. The mortality total and daily new death profile of selected countries are depicted in Figures 1 and 2. Total death till June 13-2020 due COVID-19 was 425, 931 (Figure 3).

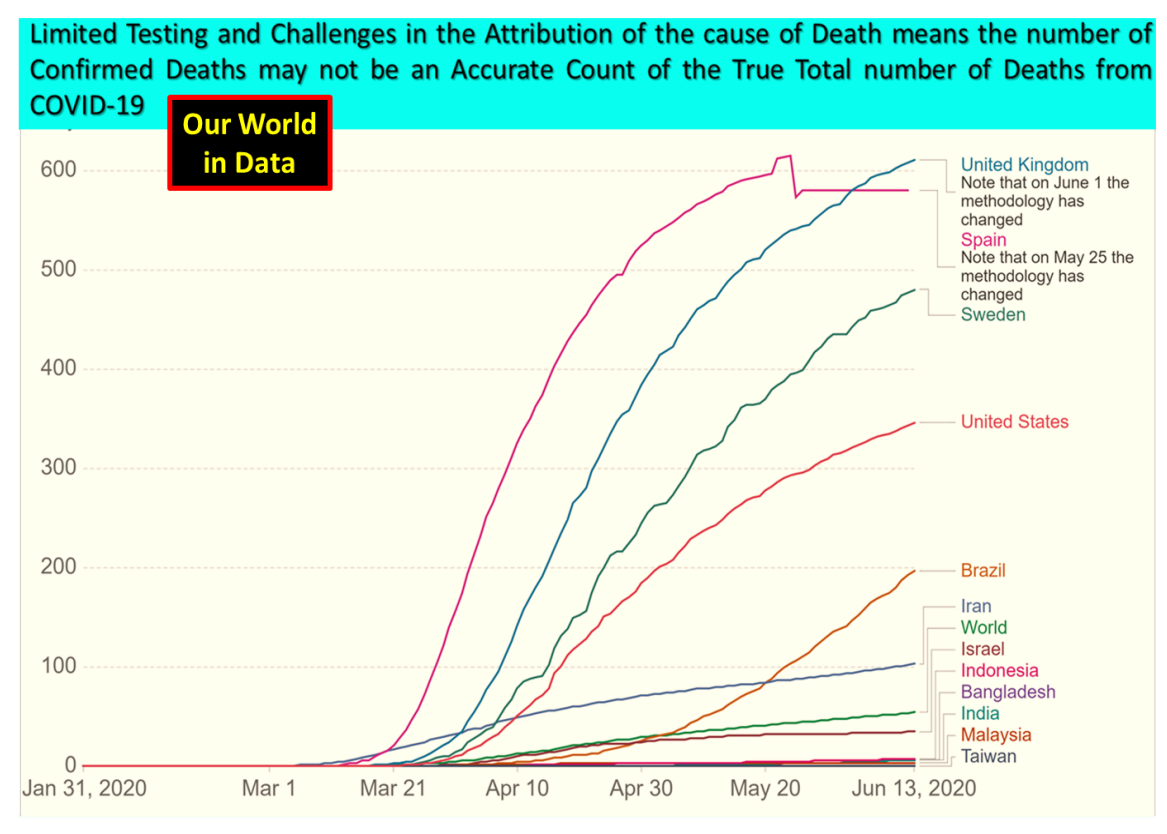

Source: European CDC - Situation update worldwide - Last update $13^{\text {th }}$ June 2020.

Figure 1. Illustrated total confirmed COVID-19 deaths per million people.

The World Health Organization promoted these strategies to prevent COVID-19 transmission [20]: 1) Clean your hands frequently with soap and water, or an alcohol-based hand sanitizer; 2) Conserve a safe space from any person who is coughing or sneezing; 3) Avoid touching your own eyes, nose or mouth; 4) Shield your nose and mouth with your bent elbow or tissue while you are coughing or sneezing; 5) Stay home; 6) If you develop a fever, cough and difficulty breathing, urgently seek medical care; 7) Comply and conform the directions of your local health authority; 8) Avoid unnecessary visits to clinics and hospitals facilities that will reduce the possibility of acquiring COVID-19 infection; additionally, permits healthcare systems to function more efficiently, consequently protecting you and others. 


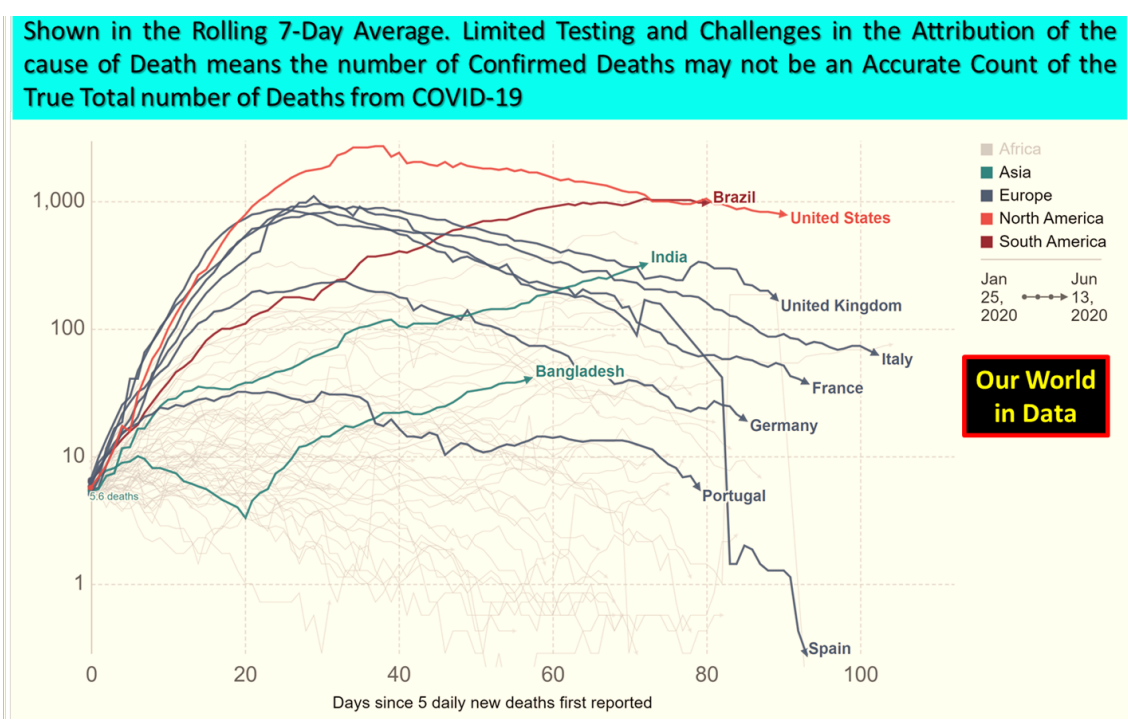

Source: European CDC - Situation update worldwide - Last update $14^{\text {th }}$ June 2020.

Figure 2. Illustrated daily new COVID-19 deaths.

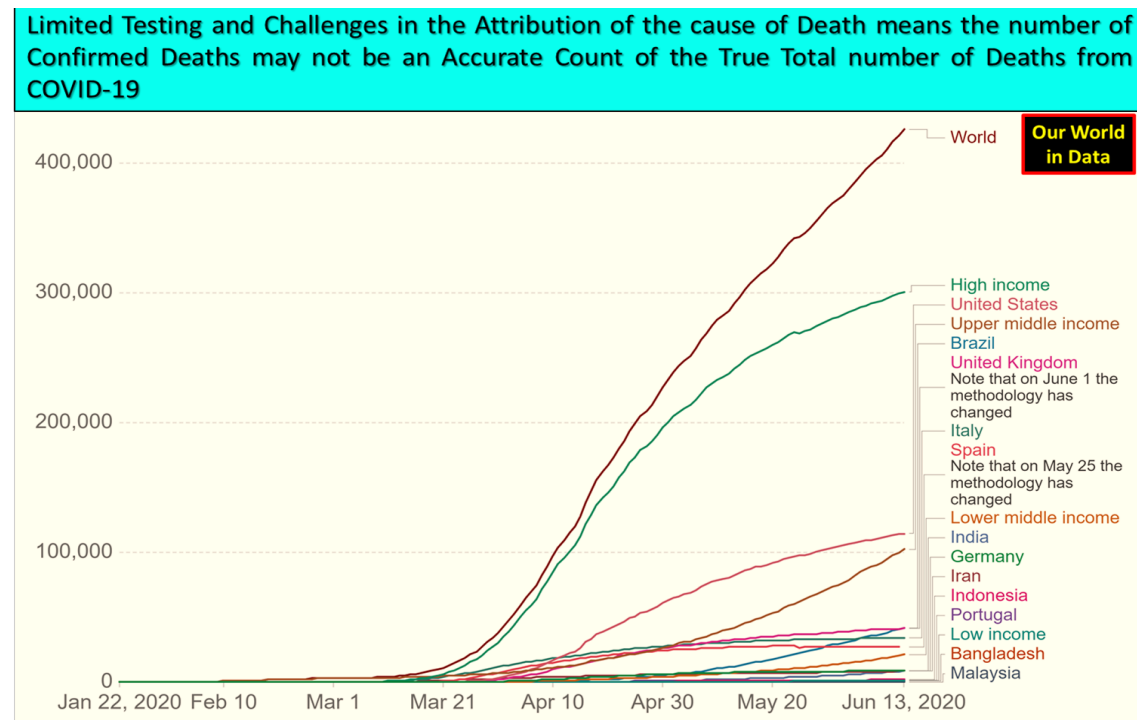

Source: European CDC - Situation update worldwide - Last update $13^{\text {th }}$ June 2020.

Figure 3. Total confirmed COVID-19 deaths in world, high, upper-middle, lower-middle, low-income, and a few selected countries.

\section{COVID-19 and Intensive Care Unit}

Coronaviruses are an outsized family of viruses that are recognized to driving force sickness extending from the common cold to more ascetic illnesses such as MERS, SARS, and the current global pandemic of COVID-19 [21,22]. There is no explicit pharmacological intervention, curative treatment, and vaccine caused by the novel coronavirus [21,23]. Nevertheless, many of the pathological issues of COVID-19 currently managed with available clinical options, and consequently, current treatment planning principally founded on the individual patients' clinical context [24-26]. Additionally, COVID-19 patients frequently need supportive medical care, including the Intensive Care Unit with ventilator, and dialysis as these found highly effective in saving lives [27-29]. 
Collaborative research of WHO and the Chinese Government reported that $6.1 \%$ of COVID-19 patients were categorized as critically sick with respiratory failure, shock, and impaired function multiple vital organs or even failure [30]. Additionally, $13.8 \%$ of patients develop severe dyspnea with respiratory rate $30 / 30+$ per minute, oxygen saturation $93 \%$ or less, the partial pressure of arterial oxygen to fraction of inspired oxygen $\left[\mathrm{PaO}_{2} / \mathrm{FiO}_{2}\right]$ ratio below $300 \mathrm{~mm} \mathrm{Hg}$, and increase in lung infiltrates over 50\% within 24-48 hours [30].

All severe cases of COVID-19 do not need ICU service and care. Certainly, ICU admissions are reliant on the harshness of disease and the ICU availability of the healthcare system [27]. One Italian study reported that among the 1581 COVID-19 patients with ICU related data (March/2020). This study out of 1581 patients 920 (58\%; 95\% CI 56\%-61\%) were continued in the ICU, 256 (16\%; 95\% CI 14\%-18\%) were cured and released from the ICU, and 405 (26\%; 95\% CI 23\%-28\%) had passed away in the ICU. Elderly patients (n=786; age 64 years and above) had higher rate of death than younger patients $(n=795$; age 63 years or below) (36\% vs. 15\%; difference, $21 \%$; $95 \%$ CI $17 \%-26 \%$; p $<0.001)$. After that, around $26 \%$ the rate of the fatal outcome of COVID-19 in Italy [31].

One Canadian study conducted between February to April/2020 among 117 diagnosed case of COVID-19 required ICU care and service. The age range was 60-75 years, and $67.5 \%$ and $32.5 \%$ were male and female, respectively. Additionally, $73.5 \%$ of patients admitted in ICU have as a minimum one comorbidity and $63.2 \%$ required invasive mechanical ventilation. Overall, the duration of mechanical ventilation was 13.5 days (Interquartile Range; IQR = 8-22) and 11 days $(\mathrm{IQR}=6-16)$ for patients achieved good clinical outcomes and released. A total of $15.4 \%$ of patients had died till May/2020, 10.3\% patients' improvement was slow and continued the need of the ICU care, and 13.7\% were released from the ICU but endured in hospital, and $60.7 \%$ were cured, released from the hospital and reached home [32].

One the US reported that out of twenty-four definite COVID-19 patients admitted in ICU service, $58 \%$ had diabetes mellitus. Among these patients, $50 \%$ of cases passed away from day-1 to day- 8 . Remaining $50 \%$ patients survived, $21 \%$ were cured, released and go home, $17 \%$ were released from the ICU care, but the improvement was not enough, thereby, need to stay in the hospital, and $12 \%$ patients were not improved and needed continuing to receive mechanical ventilation in the ICU. The study concluded that the full picture requiring the ICU service was a hypoxemic respiratory failure [33].

A prospective study was conducted in hospitals allied with Columbia University, New York, USA, between March/2020 to April/2020. In this time frame, 1150 cases of laboratory-confirmed COVID-19 were admitted, and among them, $22 \%$ were in severe condition. The median age of these COVID-19 patients was 62 years (IQR 51-72); additionally, 67\% and 33\% were men and women, respectively. Moreover, $82 \%$ of admitted patients had at least one comorbidity, such as hypertension (63\%), diabetes (36\%), and obesity (46\%). Among these admitted cases, $39 \%$ and 37\% were passed away and continued hospitalization till April/2020. Invasive mechanical ventilation was required among $79 \%$ cases for a median of 18 days (IQR 9-28), with $31 \%$ need hemodialysis. Among these patients very seriously deteriorated by the median time three days (IQR 1-6). This study found among the elderly population (Adjusted Hazard Ratio; aHR = 1.31; 1.09-1.57) per 10-year increase). The statistical analysis when conducted among non-communicable-disease comorbidity revealed that chronic cardiac disease, chronic pulmonary disease, higher concentrations of interleukin-6, and higher concentrations of D-dimer were exclusively correlated with hospital-admitted patients' mortality $(\mathrm{aHR}=1.76$; 1.08-2.86), $(\mathrm{aHR}=2.94 ; 1.48-5.84),(\mathrm{aHR}=1.11 ; 95 \% \mathrm{CI} 1.02-1.20 ;$ per decile increase $),(\mathrm{aHR}=1.10 ; 1.01-1.19$; per decile increase), respectively [34]. 
The Scottish Government has proclaimed till June/2020 that a total of 220,198 Scottish population have been examined for COVID-19. Among these, 202,121 and 18,077 were confirmed negative and positive, respectively [35]. In Scotland, those patients admitted ICUs 38\% of COVID-19 do not recover and expire [36]. Among Scottish patients required ICUs, they need about 80\%, almost $80 \%$, and nearly $30 \%$ required advanced respiratory support, cardiovascular support, and dialysis, respectively [36]. Médecins Sans Frontières [(MSF) Doctors Without Borders] reported in Brazil, between 15,000-30,000 are infected with COVID-19 every day, over 43,000 passed away and closely 870,000 cases. Additionally, the mortality rate is highest among nursing staff in Brazil than any other country around the planet. Around one hundred nurses are dying every month because of the global pandemic of COVID-19 [37]. Nevertheless, another study reported in June/2020 that in Brazil, total COVID-19 cases (Figure 4), mortality (Figure 5), and recovered was $983,359,47,869$, and 520,360, respectively [38].

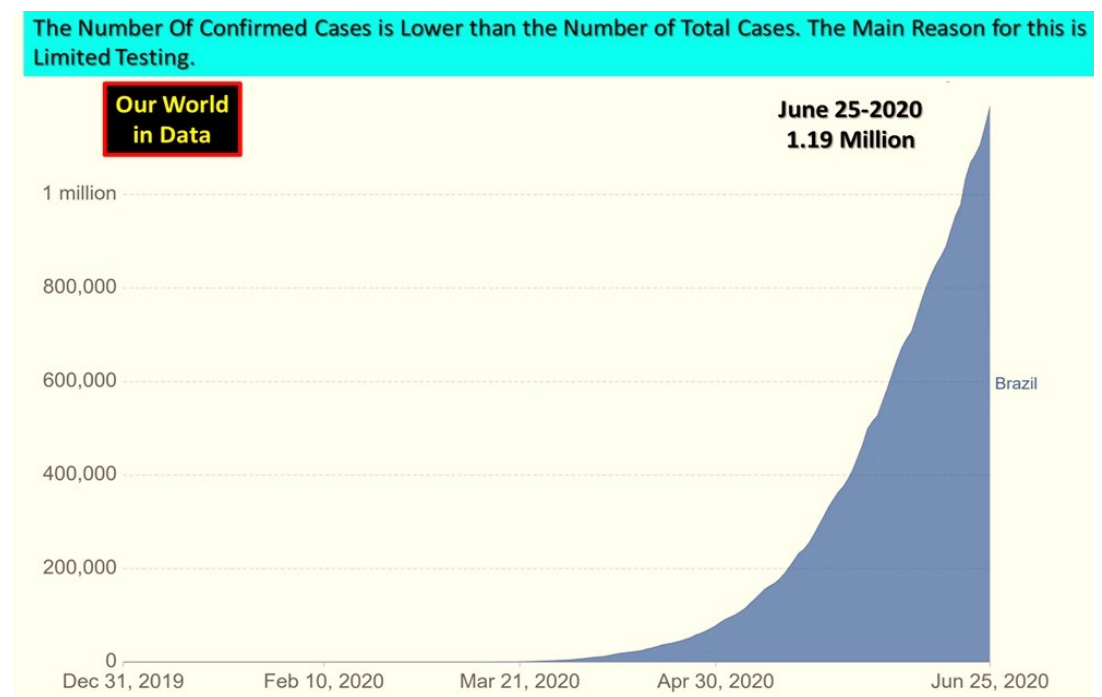

Source: European CDC - Situation update worldwide - Last update $25^{\text {th }}$ June 2020.

Figure 4. Illustrated total confirmed COVID-19 cases.

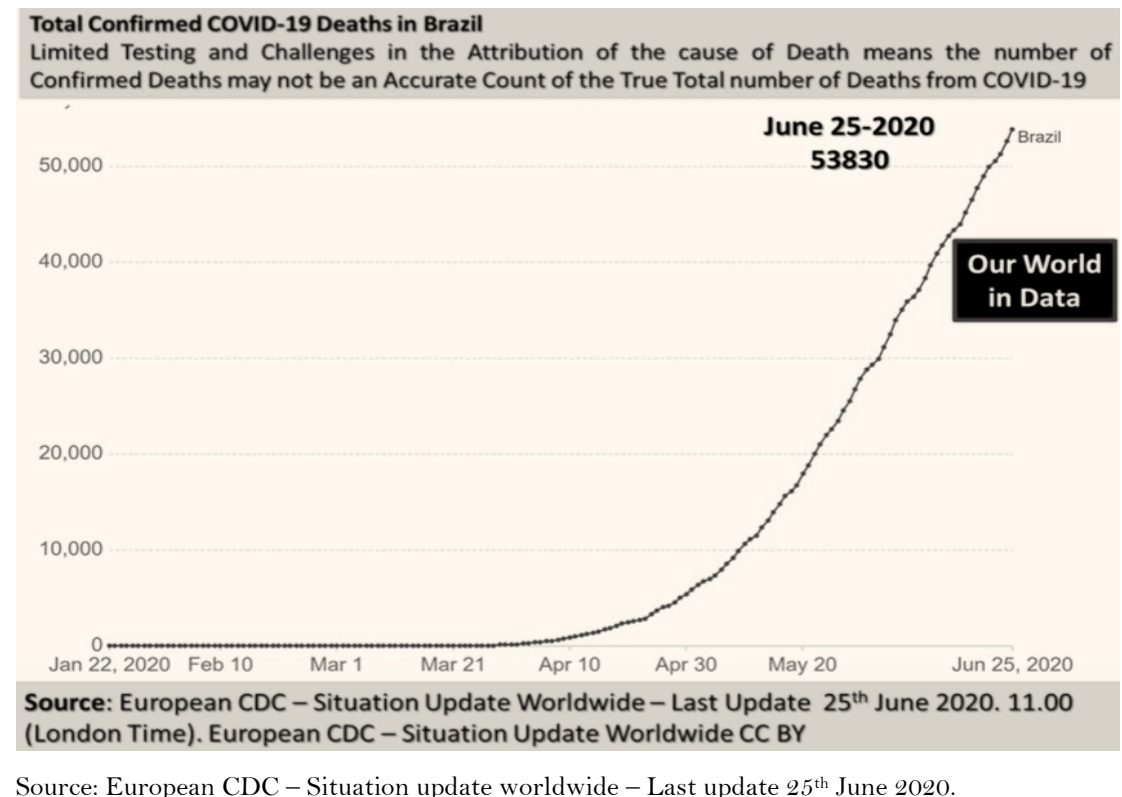

Figure 5. Total confirmed COVID-19 deaths in Brazil. 


\section{Currently Utilized Medication for COVID-19: Clinically Approved for Other Indication}

Currently, there are no specific and approved medicines for the treatment of COVID-19 infections. Though there are a lot of efforts are ongoing. Subsequently, a systematic review was conducted based on currently published research regarding chloroquine (CQ) and hydroxychloroquine (HCQ). This study supported the utilization of both $\mathrm{CQ}$ and HCQ - as because two medicines are in clinical use for 86 years for other diseases like malaria, rheumatoid arthritis, and systemic lupus erythematosus. This review revealed the risk regarding these age-old medicines at minimum risk. As there has been enough time has passed to study post-market surveillance. Moreover, both medications are cost-effective; additionally, HCQ is approved in many countries, since 2014 as a third- or fourth-line drug, diabetes mellitus [39].

Similarly, multiple studies reported that efficacy and safety issues are worth utilizing CQ and HCQ in the absence of specific drugs to combat the global pandemic [40-42]. On the contrary, June 15, 2020, the US Food and Drug Administration (FDA) rescinded the emergency use authorization (EUA) that permitted CQ and HCQ to use for the treatment of COVID-19 hospitalized patients. The FDA assessed that the allowable principles for allotting a EUA are no longer come across. After that, the FDA decided CQ and HCQ are not effective and safe in treating COVID-19 under the EUA provision. The decision to canceled EUA was based on evolving scientific data and constant analysis of the clinical outcome [43].

A recent systematic review and meta-analysis reported that studies, although HCQ + azithromycin (Azi) appears safe and effective. Nevertheless, more multi research studies with large data sizes are obligatory for an ultimate inference. Additionally, this review reported that HCQ has better shreds of evidence and promising efficacy and safety profile to avert radiological progression (deterioration) of COVID-19 cases when compared with control or conventional treatment group [44]. The French group of researchers reported that HCQ + Azi combination when applied to COVID-19 patients, it was successfully eradicated $100 \%$ virological load when compared with the HCQ alone (57.1\%) and the control (12.5\%) group [45]. The same research group in their second study with a higher number sample size revealed that HCQ + Azi combination reduces $83 \%$ and $93 \%$ of the virological load of COVID-19 cases on day-seven and day-eight, respectively. It was reported that $81.25 \%$ were cured and released from the hospital [46]. The identical research cluster in their third study with an additional number sample than the second study reported that HCQ + Azi combination diminishes $91.7 \%$ of the virological load among COVID-19 patients by day-ten and the unfortunate clinical consequence was observed in only $4.3 \%$ patients, and $0.47 \%$ patients passed away [47].

Another French group of researchers 48 working separately revealed quite the reverse findings and were unsuccessful in imitating the earlier results [45-47]. The case selection of this study was much different [48]. These COVID-19 patients belong to the severe category with multiple substantial comorbidities like carcinoma, HIV, and over-weight [48]. It was reported that HCQ + Azi combination causes mild adverse drug reactions (ADRs) that include nausea, vomiting, diarrhea, and blurring of vision [46]. Another study reported that only one of their study participants developed electrocardiographic changes of QT prolongation [48]. Another study showed that $11 \%$ of research participants of COVID-19 cases with these combination antimicrobials developed substantial QTc prolongation. Additionally, those cases develop of acute renal failure was an imperative forecaster of extreme QTc prolongation [49].

A study was conducted in New York among 1438 COVID-19 hospitalized male patients with a median age of 63 years receiving HCQ, Azi, or both. This study revealed that in general COVID-19 hospital admitted patients' death rate was $20.3 \%$ (95\% CI; $18.2 \%-22.4 \%)$. The possibility of passing-away for patients receiving HCQ + Azi was 189/735 (25.7\%; 95\% CI 22.3\%-28.9\%), HCQ alone, 54/271 (19.9\%; 95\% CI 15.2\%-24.7\%), Azi 
alone, $21 / 211$ (10.0\%; 95\% CI 5.9\%-14.0\%), and not-at-al medication, 28/221 (12.7\%; 95\% CI 8.3\%-17.1\%). In adjusted Cox proportional hazards models when compared with patients receiving not either medicine, there were no statistically significant differences observed regarding death rate for patients receiving $\mathrm{HCQ}+\mathrm{Azi}$ $(\mathrm{HR}=1.35 ; 95 \%$ CI 0.76-2.40), HCQ singly $(\mathrm{HR}=1.08 ; 95 \%$ CI 0.63-1.85), or Azi exclusively $(\mathrm{HR}=0.56$; 95\% CI 0.26-1.21). In logistic models analysis found patients receiving none of two cardiac arrests was significantly more expected among patients receiving HCQ + Azi (Adjusted OR = 2.13; 95\% CI 1.12-4.05), but not hydroxychloroquine singly (Adjusted OR = 1.91; 95\% CI 0.96-3.81) or Azi solely (Adjusted OR = 0.64; 95\% CI 0.27-1.56). In adjusted logistic regression models, there were no statistically significant changes observed in the comparative possibility of atypical electrocardiogram results. Consequently, this study finally concluded that pharmacological intervention with HCQ, Azi, alone, or HCQ + Azi (combination) was not correlated with statistically significantly in lowering mortality, among COVID-19 hospitalized patients [50]. As there are no definite or specific treatment options, by this means, the global pandemic COVID-19 initiated available medicine repurposing is viewed as the instantaneous choice [51].

\section{Computational Drug Repurposing and Repositioning}

Computational drug repurposing (as well recognized as drug repositioning) intentions at identifying new clinical indication for by now available and clinically utilized for indication, exclusively when the thorough 3D structures of significant viral proteins are invented within five days [52-54]. Drug repurposing has developed as a dynamic division of medicine invention for novel clinical indication [52].

Accordingly, there has been a blast in drug repurposing experiments to invent innovative medicines as aspirants and research studies regarding circumstantial findings. One second-generation cephalosporin Cefuroxime has been spotted with quite a lot of anecdotal benefits in the treatment of COVID-19 [51]. In that way, one scoping review reported that cefuroxime reveals promising efficacy in opposing three significant COVID-19 proteins necessary for replication in drug repurposing experimentations. In this manner, cefuroxime possibly possesses auspicious multi-target pharmacodynamics that can help us to combat the current pandemic [51]. Additionally, cefuroxime was approved by the US FDA in 1998. Subsequently, it has a long history for clinical use and post-market-surveillance that raises it as a reliable alternative for additional research studies in the global battle against COVID-19 - the current highest threat of human existence [51,55].

Computational drug repurposing studies have already identified several clinically available medicines that possess potential pharmacodynamics to inhibit COVID-19 principal protease responsible for viral replication and transcription. Those antimicrobials include - carfilzomib, eravacycline, valrubicin, lopinavir, lopinavir-ritonavir, tipranavir, raltegravir taxifolin rhamnetin, elbasvir, ivermectin, and many more upcoming [54,56-60].

Ivermectin was FDA-approved for parasitic infections in 1996 for the treatment of strongyloidiasis and onchocerciasis [61]. However, ivermectin is an antiparasitic medicine but possesses a broad-spectrum antiviral activity in experimental studies outside of a living organism, including the COVID-19 virus [59]. It has around 5000 times the potential to reduce viral load at 48 hours in cell-line culture [59]. Another study reported similarly that ivermectin possesses broad-spectrum antiviral efficacy to inhibit viral replication and transcription of numerous animal and human viruses, which include both RNA and DNA viruses. The broadspectrum antiviral property of ivermectin depends on through the inhibition of importin $\alpha / \beta$-mediated nuclear transport of viral proteins. The identical pharmacodynamics of ivermectin was observed with COVID-19. This 
study finally concluded that the beneficial clinical potential and ADRs of ivermectin yet not adequately assessed in prescribing COVID-19 patients [60].

\section{Convalescent Plasma Therapy}

Passive immunization (PI) and antibody therapy had been over a hundred years back. After that, convalescent plasma therapy is a long-standing therapeutic resource with new evidence for the discouragement and treatment of hypoimmunoglobulinemias, carcinoma, and human infectious diseases such as measles, hepatitis A, hepatitis B, tetanus, varicella, rabies, and vaccinia [62-64].

The availability and easy accessibility of antimicrobials had put down, and PI therapy issues went exile and considered as out-of-date treatment options for especially infectious diseases [63]. The advent of multi-drug resistant (MDR) pathogenic microbial contagious diseases, and laterally with the initiation of novel monoclonal antibody synthesis methods has to reawaken, and PI technique has been returned in clinical medicine PI [63].

Convalescent plasma had been prescribed as the last remedy among gravely sick SARS patients who were continued to worsen despite having methylprednisolone. Additionally, multiple research reported that convalescent plasma reduces hospital stay and death rates than those who did not have [65-68]. WHO in 2014 recommended prescribing and utilizing convalescent plasma as an empirical therapeutic option during the Ebola epidemic in Western Africa [69,70]. A similar treatment code of practice had been developed to use convalescent plasma as a last resort for therapeutic intervention among severely sick MERS patients' management program in 2015 [71,72].

The mortality risk of COVID-19 infection, pneumonia, and acute respiratory distress syndrome (ARDS) among critically ill patients over 65 years old remains extremely high, around 12\%. It was observed these patients passed away by one to two weeks after admitted in ICU [ 73,74]. Multiple studies have been reported that human convalescent plasma of COVID-19 patients appeared to be a safe and possesses high prospect and possibilities for beneficial effects among the current global epidemic patients and asymptomatic cases with exposure to COVID-19 sick individual [21,75-77]. Multiple recent research studies reported that convalescent plasma therapy was well tolerated among COVID-19 patients and improved the clinical consequences through reducing viral load and deactivating coronavirus virulence potential [78-81]. Nonetheless, it is judgmentally imperative to conduct well-designed controlled clinical studies to establish efficacy, the optimum number of convalescent plasma transfusion, and to ascertain the appropriate time of administration. Thereby determine the clinical benefit of convalescent plasma therapy, and it can be generalized to notify the rationality of convalescent plasma therapy has been developed based on scientifically proven evidence $[75,78]$.

\section{Role of Clinical Available Antiviral Medication in COVID-19}

The US FDA issued a EUA for the broad-spectrum antiviral agent remdesivir for severe laboratory polymerase chain reaction (PCR) positive cases or suspected COVID-19 hospital admitted to both adults and pediatric patients $[82,83]$. Remdesivir is a nucleotide analog RNA polymerase inhibitor. The clinical trial was conducted in the Democratic Republic of Congo regarding remdesivir efficacy on Ebola virus infections revealed insubstantial clinical advantageous potential [84].

Multiple studies showed that remdesivir exhibits potential pharmacodynamics to inhibit replication and transcription of other human coronaviruses such as SARS-CoV in 2003 and MERS-CoV in 2012 [85-87]. 
Additionally, remdesivir antiviral pharmacodynamic was evidenced in animal models that have been confirmed for SARS-CoV and MERS-CoV [85]. It has been reported that Remdesivir is one of the top computational drug repurposing, and repositioning agents possess promising pharmacodynamics to combat COVID-19 $[88,89]$.

Multiple studies reported that Remdesivir is one of the top computational drug repurposing, and repositioning agents possess promising pharmacodynamics to combat COVID-19 [88-90]. On the contrary, some studies indicated that remdesivir was not correlated with statistically significant clinical benefits among severe COVID-19 patients [91,92]. One systematic review comprising of twenty original studies regarding lopinavir-ritonavir antiviral efficacy against COVID-19. Among these studies, twenty, one, and one research studies were conducted in China, South Korea, and Singapore, respectively. The current systematic review revealed that there were no sharply identified antiviral pieces of evidence found with this combination (lopinavir-ritonavir) in improving COVID-19 patients or not. The present state of affairs of the global pandemic of COVID-19 is a severe 'red flag" for universal health-related organizations, including WHO [93]. This study finally concluded that the current global pandemic - COVID-19 and yet to come epidemics, healthrelated organizations including WHO should trail more pre-emptive activities and well-designed strategy for clinical trials to obtain high-quality clinical results that can face imminent epidemics [93].

\section{Systemic Corticosteroids}

WHO, in general, does not recommend corticosteroids are for the treatment of COVID-19 pneumonia [94]. Additionally, it was reported that the use of systemic glucocorticoids in the treatment of acute respiratory distress syndrome (ARDS) secondary to viral pneumonia is debatable [95]. The reason for nonrecommendation glucocorticoids; as the administration of these steroids lengthen and protract viral clearance and increased risk of secondary infection [96]. Even though there are not much data available regarding the use of glucocorticoids among COVID-19 pneumonia [96], nevertheless, mostly, no single exclusive evidence subsists to anticipate that patients with COVID-19 infection can improve with glucocorticoids.

Moreover, researchers have intense apprehension of worsening and further aggravation of the disease process [97]. Furthermore, earlier studies regarding SARS and MERS revealed that no correlation of glucocorticoids with deterring mortality. Nonetheless, steroids' administration correlated with deferred viral clearance from the pulmonary tree and blood and elevated possibilities of complications, including hyperglycemia, psychosis, and avascular necrosis [98,99]. Additionally, one systematic review and metaanalysis comprising of ten research studies in 2029 among 6548 influenza caused pneumonia patients. This study found that glucocorticoids were correlated with an increased risk of mortality (Risk Ratio $=1.75 ; 95 \% \mathrm{CI}$ 1.30-2.36; $\mathrm{p}=0.0002$ ), and secondary infections (Risk Ratio $=1.98 ; 95 \%$ CI 1.04-3.78, p=0.04) [100].

COVID-19 has elicited a vast number of deaths and remarkable economic destruction give rise to international threat not only for healthcare but also in every aspect of life. Henceforth, the current pandemic of COVID-19 identified the pressing necessity of therapeutic options with specific antiviral pharmacodynamic against SARS-CoV-2. The globe needs to wait and look forward to new scientific development to fightback with COVID-19. In the meantime, preventive measures are considered as the best possible way. Finally, COVID-19 teaches us the healthcare system almost all countries need to total overhaul based on primary health care policy planning to fight against any future or health crisis [101-107]. 


\section{Conclusion}

The COVID-19 pandemic has currently gone into a catastrophic new chapter. The earlier epidemic of SARS and MERS was much slower to spread around the globe than COVID-19. Increased globalization, international traveling, and virus adaptability in almost all countries equally often reported as the primary reasons for rapid spread. Another reason frequently appeared globally risk assessment regarding COVID-19 virulence capacity the globe fails to appraise in time. To date, there is no single specific therapeutic option for battling against this virus.

\section{Authors' Contributions}

MH (D) 0000-0002-6124-7993 Conceptualization, Investigation, Formal Analysis, Writing - Original Draft Preparation and Writing - Review and Editing.

All authors declare that they contributed to critical review of intellectual content and approval of the final version to be published.

\section{Financial Support}

None.

\section{Conflict of Interest}

The authors declare no conflicts of interest.

\section{References}

[1] Balkhair AA. COVID-19 pandemic: a new chapter in the history of infectious diseases. Oman Med J 2020; $35(2):$ :e123. https://doi.org/10.5001/omj.2020.41

[2] Basak S, Singh P, Rajurkar M. Multidrug-resistant, and extensively drug-resistant bacteria: a study. J Pathog 2016; 2016:4065603. https://doi.org/10.1155/2016/4065603

[3] Magiorakos AP, Srinivasan A, Carey RB, Carmeli Y, Falagas ME, Giske CG, et al. Multidrug-resistant, extensively drug-resistant and pandrug-resistant bacteria: an international expert proposal for interim standard definitions for acquired resistance. Clin Microbiol Infect 2012; 18(3):268-81. https://doi.org/10.1111/j.1469-0691.2011. 03570.x

[4] Morens DM, Fauci AS. Emerging infectious diseases: threats to human health and global stability. PLoS Pathog 2013; 9(7):e1003467. https://doi.org/10.1371/journal.ppat.1003467

[5] World Health Organization. Disease outbreaks by year. Available from: https://www.who.int/csr/don/archive/year/en/. [Accessed June 14, 2020].

[6] Balkhair A. The struggle against pandemic influenza A (H1N1) 2009. Sultan Qaboos Univ Med J 2009; 9(3):257-60.

[7] Triana-Baltzer GB, Gubareva LV, Nicholls JM, Pearce MB, Mishin VP, Belser JA, et al. Novel pandemic influenza $\mathrm{A}\left(\mathrm{H}_{1} \mathrm{~N}_{1}\right)$ viruses are potently inhibited by DAS181, a sialidase fusion protein. PLoS One 2009; 4(11):e7788. https://doi.org/10.1371/journal.pone.0007788

[8] Balkhair A, Al Maamari K, Alawi FB. The struggle against MERS-CoV (the novel Coronavirus). Oman Med J 2013; 28(4):226-7. https://doi.org/10.5001/omj.2013.66

[9] Triana-Baltzer GB, Gubareva LV, Klimov AI, Wurtman DF, Moss RB, Hedlund M, et al. Inhibition of neuraminidase inhibitor-resistant influenza virus by DAS181, a novel sialidase fusion protein. PLoS One 2009; 4(11):e7838. https://doi.org/10.1371/journal.pone.0007838

[10] Sutton TC, Subbarao K. Development of animal models against emerging coronaviruses: from SARS to MERS coronavirus. Virology 2015; 479-480:247-58. https://doi.org/10.1016/j.virol.2015.02.030

[11] de Wit E, van Doremalen N, Falzarano D, Munster VJ. SARS and MERS: recent insights into emerging coronaviruses. Nat Rev Microbiol 2016; 14(8):523-34. https://doi.org/10.1038/nrmicro.2016.81

[12] Liu J, Zheng X, Tong Q, et al. Overlapping and discrete aspects of the pathology and pathogenesis of the emerging human pathogenic coronaviruses SARS-CoV, MERS-CoV, and 2019-nCoV. J Med Virol 2020; 92(5):491-4. https://doi.org/10.1002/jmv.25709

[13] Coronaviridae Study Group of the International Committee on Taxonomy of Viruses. The species severe acute respiratory syndrome-related coronavirus: classifying 2019-nCoV and naming it SARS-CoV-2. Nat Microbiol 2020; 5(4):536-44. https://doi.org/10.1038/s41564-020-0695-Z 
[14] Yu WB, Tang GD, Zhang L, Corlett RT. Decoding the evolution and transmissions of the novel pneumonia coronavirus (SARS-CoV-2 / HCoV-19) using whole genomic data. Zool Res 2020; 41(3):247-57. https://doi.org/10.24272/j.issn.2095-8137.2020.022

[15] Malik YS, Sircar S, Bhat S, Sharun K, Dhama K, Dadar M, et al. Emerging novel coronavirus (2019-nCoV)-current scenario, evolutionary perspective based on genome analysis and recent developments. Vet $Q$ 2020; 40(1):68-76. https://doi.org/10.1080/01652176.2020.1727993

[16] Xu X, Chen P, Wang J, Feng J, Zhou H, Li X, et al. Evolution of the novel coronavirus from the ongoing Wuhan outbreak and modeling of its spike protein for risk of human transmission. Sci China Life Sci 2020; 63(3):457-60. https://doi.org/10.1007/s11427-020-1637-5

[17] Gallegos A. WHO Declares Public Health Emergency for Novel Coronavirus. Medscape Medical News 2020. Available from: https://www.medscape.com/viewarticle/924596. [Accessed June 14, 2020].

[18] Ramzy A, McNeil DG. WHO Declares Global Emergency as Wuhan Coronavirus Spreads. The New York Times. 2020. Available from: https://nyti.ms/2RER70M. [Accessed June 14, 2020].

[19] The New York Times. Coronavirus Live Updates: WHO Declares Pandemic as Number of Infected Countries Grows. The New York Times. 2020. Available from: https://www.nytimes.com/2020/03/11/world/coronavirusnews.html\#link-682e5bo6. [Accessed June 14, 2020].

[20] World Health Organization. Coronavirus Disease (COVID-19) Advice for the Public. 2020. Available from: https://www.who.int/emergencies/diseases/novel-coronavirus-2019/advice-for-public. [Accessed June 14, 2020].

[21] Li H, Liu SM, Yu XH, Tang SL, Tang CK. Coronavirus disease 2019 (COVID-19): current status and future perspectives. Int J Antimicrob Agents 2020; 55(5):105951. https://doi.org/10.1016/j.ijantimicag.2020.105951

[22] Ahn DG, Shin HJ, Kim MH, Lee S, Kim HS, Myoung J, et al. Current status of epidemiology, diagnosis, therapeutics, and vaccines for novel coronavirus disease 2019 (COVID-19). J Microbiol Biotechnol 2020; 30(3):313-24. https://doi.org/10.4014/jmb.2003.03011

[23] Lythgoe MP, Middleton P. Ongoing clinical trials for the management of the COVID-19 pandemic. Trends Pharmacol Sci 2020; 41(6):363-82. https://doi.org/10.1016/j.tips.2020.03.006

[24] Saber-Ayad M, Saleh MA, Abu-Gharbieh E. The rationale for potential pharmacotherapy of COVID-19. Pharmaceuticals 2020; 13(5):E96. https://doi.org/10.3390/ph13050096

[25] Jean SS, Lee PI, Hsueh PR. Treatment options for COVID-19: The reality and challenges. J Microbiol Immunol Infect 2020; 53(3):436-43. https://doi.org/10.1016/j.jmii.2020.03.034

[26] Jean SS, Hsueh PR. Old and re-purposed drugs for the treatment of COVID-19. Expert Rev Anti Infect Ther 2020; 15. https://doi.org/10.1080/14787210.2020.1771181

[27] Phua J, Weng L, Ling L, Egi M, Lim CM, Divatia JV, et al. Intensive care management of coronavirus disease 2019 (COVID-19): challenges and recommendations. Lancet Respir Med 2020; 8(5):506-17. https://doi.org/10.1016/S2213-2600(20)30161-2

[28] Murthy S, Gomersall CD, Fowler RA. Care for critically ill patients with COVID-19. JAMA 2020; 10.1001/jama.2020.3633. https://doi.org/10.1001/jama.2020.3633

[29] Shang Y, Pan C, Yang X, Zhong M, Shang X, Wu Z, et al. Management of critically ill patients with COVID-19 in ICU: statement from front-line intensive care experts in Wuhan, China. Ann Intensive Care 2020; 10(1):73. https://doi.org/10.1186/s13613-020-00689-1

[30] WHO-China Joint Mission. Report of the WHO-China Joint Mission on Coronavirus Disease 2019 (COVID-19). 2020. Available from: https://www.who.int/docs/default-source/coronaviruse/who-chinajoint-mission-on-covid-19final-report.pdf. [Accessed June 16, 2020].

[31] Grasselli G, Zangrillo A, Zanella A, Antonelli M, Cabrini L, Castelli A, et al. Baseline characteristics and outcomes of 1591 patients infected with SARS-CoV-2 admitted to ICUs of the Lombardy Region, Italy. JAMA 2020; 323(16):1574-81. https://doi.org/10.1001/jama.2020.5394

[32] Mitra AR, Fergusson NA, Lloyd-Smith E, Wormsbecker A, Foster D, Karpov A, et al. Baseline characteristics and outcomes of patients with COVID-19 admitted to intensive care units in Vancouver, Canada: a case series. CMAJ 2020; cmaj.200794. https://doi.org/10.1503/cmaj.200794

[33] Bhatraju PK, Ghassemieh BJ, Nichols M, Kim R, Jerome KR, Nalla AK, et al. Covid-19 in critically ill patients in the Seattle region - case series. N Engl J Med 2020; 382(21):2012-22. https://doi.org/10.1056/NEJMoa2004500

[34] Cummings MJ, Baldwin MR, Abrams D, Jacobson SD, Meyer BJ, Balough EM, et al. Epidemiology, clinical course, and outcomes of critically ill adults with COVID-19 in New York City: a prospective cohort study. Lancet 2020; 395(10239):1763-70. https://doi.org/10.1016/So140-6736(20)31189-2

[35] The Scottish Government. Coronavirus (COVID-19): Daily Data for Scotland. 2020. Available from: https://www.gov.scot/publications/coronavirus-covid-19-daily-data-for-scotland/\#page-top. [Accessed June 19, 2020].

[36] Public Health Scotland. Scottish Intensive Care Society Audit Group report on COVID-19. 2020. Available from: https://beta.isdscotland.org/find-publications-and-data/population-health/covid-19/scottish-intensive-care-societyaudit-group-report-on-covid-19/. [Accessed June 19, 2020]. 
[37] Médecins Sans Frontières. Coronavirus COVID-19 pandemic. Brazil's COVID-19 nightmare is far from under control. 2020. Available from: https://www.msf.org/coronavirus-covid-19-nightmare-continues-brazil. [Accessed June 19, 2020].

[38] WorldOMeter.

$$
\text { World, Countries, Brazil. }
$$$$
2020 .
$$

Available

from: https://www.worldometers.info/coronavirus/country/brazil/. [Accessed June 19, 2020].

[39] Singh AK, Singh A, Shaikh A, Singh R, Misra A. Chloroquine and hydroxychloroquine in the treatment of COVID-19 with or without diabetes: a systematic search and a narrative review with a special reference to India and other developing countries. Diabetes Metab Syndr 2020; 14(3):241-6. https://doi.org/10.1016/j.dsx.2020.03.011

[40] Meo SA, Klonoff DC, Akram J. Efficacy of chloroquine and hydroxychloroquine in the treatment of COVID-19. Eur Rev Med Pharmacol Sci 2020; 24(8):4539-47. https://doi.org/10.26355/eurrev_202004_21038

[41] Shittu MO, Afolami OI. Improving the efficacy of chloroquine and hydroxychloroquine against SARS-CoV-2 may require zinc additives - a better synergy for future COVID-19 clinical trials. Infez Med 2020; 28(2):192-7.

[42] Devaux CA, Rolain JM, Colson P, Raoult D. New insights on the antiviral effects of chloroquine against coronavirus: what to expect for COVID-19? Int J Antimicrob Agents 2020; 55(5):105938. https://doi.org/10.1016/j.ijantimicag.2020.105938

[43] The US Food and Drug Administration. Coronavirus (COVID-19) Update: FDA Revokes Emergency Use Authorization for Chloroquine and Hydroxychloroquine. FDA News Release. 2020. Available from: https://www.fda.gov/news-events/press-announcements/coronavirus-covid-19-update-fda-revokes-emergency-useauthorization-chloroquine-and. [Accessed June 19, 2020].

[44] Sarma P, Kaur H, Kumar H, Mahendru D, Avti P, Bhattacharyya A, et al. Virological and clinical cure in COVID-19 patients treated with hydroxychloroquine: a systematic review and meta-analysis. J Med Virol 2020; 92(7):776-85. https://doi.org/10.1002/jmv.25898

[45] Gautret P, Lagier JC, Parola P, Hoang VT, Meddeb L, Mailhe M, et al. Hydroxychloroquine and azithromycin as a treatment of COVID-19: results of an open-label non-randomized clinical trial. Int J Antimicrob Agents 2020; 105949. https://doi.org/10.1016/j.ijantimicag.2020.105949

[46] Gautret P, Lagier JC, Parola P, Hoang VT, Meddeb L, Sevestre J, et al. Clinical and microbiological effect of a combination of hydroxychloroquine and azithromycin in 80 COVID-19 patients with at least a six-day follow up: a pilot observational study. Travel Med Infect Dis 2020; 34:101663. https://doi.org/10.1016/j.tmaid.2020.101663

[47] Million M, Lagier JC, Gautret P, Colson P, Fournier PE, Amrane S, et al. Early treatment of COVID-19 patients with hydroxychloroquine and azithromycin: a retrospective analysis of 1061 cases in Marseille, France. Travel Med Infect Dis 2020; 101738. https://doi.org/10.1016/j.tmaid.2020.101738

[48] Molina JM, Delaugerre C, Le Goff J, Mela-Lima B, Ponscarme D, Goldwirt L, et al. No evidence of rapid antiviral clearance or clinical benefit with the combination of hydroxychloroquine and azithromycin in patients with severe COVID-19 infection. Med Mal Infect 2020; 50(4):384. https://doi.org/10.1016/j.medmal.2020.03.006

[49] Chorin E, Dai M, Shulman E, Wadhwani L, Bar-Cohen R, Barbhaiya C, et al. The QT interval in patients with COVID-19 treated with hydroxychloroquine and azithromycin. Nat Med 2020; 26(6):808-9. https://doi.org/10.1038/s41591-020-0888-2

[50] Rosenberg ES, Dufort EM, Udo T, Wilberschied LA, Kumar J, Tesoriero J, et al. Association of treatment with hydroxychloroquine or azithromycin with in-hospital mortality in patients with COVID-19 in New York State. JAMA 2020; e208630. https://doi.org/10.1001/jama.2020.8630

[51] Durojaiye AB, Clarke JD, Stamatiades GA, Wang C. Repurposing cefuroxime for treatment of COVID-19: a scoping review of in silico studies. J Biomol Struct Dyn 2020; 1-8. https://doi.org/10.1080/07391102.2020.1777904

[52] March-Vila E, Pinzi L, Sturm N, Tinivella A, Engkvist O, Chen H, et al. On the integration of in silico drug design methods for drug repurposing. Front Pharmacol 2017; 8:298. https://doi.org/10.3389/fphar.2017.00298

[53] Novac N. Challenges and opportunities of drug repositioning. Trends Pharmacol Sci 2013; 34(5):267-72. https://doi.org/10.1016/j.tips.2013.03.004

[54] Wang J. Fast identification of possible drug treatment of Coronavirus disease-19 (COVID-19) through computational drug repurposing study. J Chem Inf Model 2020; acs. jcim.Oc00179. https://doi.org/10.1021/acs.jcim.Oc00179

[55] Center for Drug Evaluation and Research. US Food \& Drug Administration. US Department of Health \& Human Services. Cefuroxime Application Number: 65002. Approval Letter. 1998. Available from: https://www.accessdata.fda.gov/drugsatfda_docs/anda/98/65002_Cefuroxime.pdf. [Accessed June 21, 2020].

[56] Kumar Y, Singh H, Patel CN. In silico prediction of potential inhibitors for the Main protease of SARS-CoV-2 using molecular docking and dynamics simulation-based drug-repurposing. J Infect Public Health 2020; S18760341(20)30526-8. https://doi.org/10.1016/j.jiph.2020.06.016

[57] Fischer A, Sellner M, Neranjan S, Smieško M, Lill MA. Potential inhibitors for novel coronavirus protease identified by virtual screening of 606 million compounds. Int J Mol Sci 2020; 21(10):3626. https://doi.org/10.3390/ijms21103626

[58] Jin Z, Du X, Xu Y, Deng Y, Liu M, Zhao Y, et al. Structure of Mpro from SARS-CoV-2 and discovery of its inhibitors. Nature 2020; 582(7811):289-93. https://doi.org/10.1038/s41586-020-2223-y 
[59] Caly L, Druce JD, Catton MG, Jans DA, Wagstaff KM. The FDA-approved drug ivermectin inhibits the replication of SARS-CoV-2 in vitro. Antiviral Res 2020; 178:104787. https://doi.org/10.1016/j.antiviral.2020.104787

[60] Sharun K, Dhama K, Patel SK, Pathak M, Tiwari R, Singh BR, et al. Ivermectin, a new candidate therapeutic against SARS-CoV-2/COVID-19. Ann Clin Microbiol Antimicrob 2020; 19(1):23. https://doi.org/10.1186/s12941-02000368-w

[61] Center for Drug Evaluation and Research. US Food \& Drug Administration. US Department of Health \& Human Services. Ivermectin Application Number: 050742. Approval Letter. 1996. Available from: https://www.accessdata.fda.gov/drugsatfda_docs/nda/96/050742ap.pdf. [Accessed June 21, 2020].

[62] Marano G, Vaglio S, Pupella S, Facco G, Catalano L, Liumbruno GM, et al. Convalescent plasma: new evidence for an old therapeutic tool? Blood Transfus 2016; 14(2):152-7. https://doi.org/10.2450/2015.0131-15

[63] Rajam G, Sampson J, Carlone GM, Ades EW. An augmented passive immune therapy to treat fulminant bacterial infections. Recent Pat Antiinfect Drug Discov 2010; 5(2):157-67. https://doi.org/10.2174/157489110791233496

[64] Keller MA, Stiehm ER. Passive immunity in prevention and treatment of infectious diseases. Clin Microbiol Rev 2000; 13(4):602-14. https://doi.org/10.1128/cmr.13.4.602-614.2000

[65] Lai ST. Treatment of severe acute respiratory syndrome. Eur J Clin Microbiol Infect Dis 2005; 24(9):583-91. https://doi.org/10.1007/s10096-005-0004-Z

[66] Soo YO, Cheng Y, Wong R, Hui DS, Lee CK, Tsang KK, et al. Retrospective comparison of convalescent plasma with continuing high-dose methylprednisolone treatment in SARS patients. Clin Microbiol Infect 2004; 10(7):676-8. https://doi.org/10.1111/j.1469-0691.2004. 00956.x

[67] Cheng Y, Wong R, Soo YO, Wong WS, Lee CK, $\mathrm{Ng} \mathrm{MH,} \mathrm{et} \mathrm{al.} \mathrm{Use} \mathrm{of} \mathrm{convalescent} \mathrm{plasma} \mathrm{therapy} \mathrm{in} \mathrm{SARS} \mathrm{patients}$ in Hong Kong. Eur J Clin Microbiol Infect Dis 2005; 24(1):44-6. https://doi.org/10.1007/s 10096-004-1271-9

[68] Chen L, Xiong J, Bao L, Shi Y. Convalescent plasma as a potential therapy for COVID-19. Lancet Infect Dis 2020; 20(4):398-400. https://doi.org/10.1016/S1473-3099(20)30141-9

[69] World Health Organization. Use of Convalescent Whole Blood or Plasma Collected from Patients Recovered from Ebola Virus Disease for Transfusion, as an Empirical Treatment during Outbreaks. Interim Guidance for National Health Authorities and Blood Transfusion Services. 2014. Available from: https://apps.who.int/iris/bitstream/handle/10665/135591/WHO_HIS_SDS_2014.8_eng.pdf;jsessionid=D535F038 941D2868A8792D84345185A6? sequence $=1$. [Accessed June 21, 2020].

[70] van Griensven J, De Weiggheleire A, Delamou A, Smith PG, Edwards T, Vandekerckhove P, et al. The use of Ebola convalescent plasma to treat Ebola virus disease in resource-constrained settings: a perspective from the field. Clin Infect Dis 2016; 62(1):69-74. https://doi.org/10.1093/cid/civ680

[71] Arabi Y, Balkhy H, Hajeer AH, Bouchama A, Hayden FG, Al-Omari A, et al. Feasibility, safety, clinical, and laboratory effects of convalescent plasma therapy for patients with Middle East respiratory syndrome coronavirus infection: a study protocol. Springerplus 2015; 4:709. https://doi.org/10.1186/s40064-015-1490-9

[72] Arabi YM, Al-Enezi F, Longuere KS, Balkhy HH, Al-Sultan M, Al-Omari A, et al. Feasibility of a randomized controlled trial to assess treatment of Middle East Respiratory Syndrome Coronavirus (MERS-CoV) infection in Saudi Arabia: a survey of physicians. BMC Anesthesiol 2016; 16(1):36. https://doi.org/10.1186/s12871-016-0198-X

[73] Yang X, Yu Y, Xu J, Shu H, Xia J, Liu H, et al. Clinical course and outcomes of critically ill patients with SARS-CoV2 pneumonia in Wuhan, China: a single-centered, retrospective, observational study. Lancet Respir Med 2020; 8(5):475-81. https://doi.org/10.1016/S22 13-2600(20)30079-5

[74] Mizumoto K, Chowell G. Estimating risk for death from Coronavirus disease, China, January-February 2020. Emerg Infect Dis 2020; 26(6):1251-6. https://doi.org/10.3201/eid2606.200233

[75] Bloch EM, Shoham S, Casadevall A, Sachais BS, Shaz B, Winters JL, et al. Deployment of convalescent plasma for the prevention and treatment of COVID-19. J Clin Invest 2020; 130(6):2757-65. https://doi.org/10.1172/JCI 138745

[76] Brown BL, McCullough J. Treatment for emerging viruses: convalescent plasma and COVID-19. Transfus Apher Sci 2020; 59(3):102790. https://doi.org/10.1016/j.transci.2020.102790

[77] Wu R, Wang L, Kuo HD, Shannar A, Peter R, Chou PJ, et al. An update on current therapeutic drugs treating COVID-19. Curr Pharmacol Rep 2020; 1-15. https://doi.org/10.1007/s40495-020-002 16-7

[78] Duan K, Liu B, Li C, Zhang H, Yu T, Qu J, et al. Effectiveness of convalescent plasma therapy in severe COVID-19 patients. Proc Natl Acad Sci U S A 2020; 117(17):9490-6. https://doi.org/10.1073/pnas.2004168117

[79] Zhao Q, He Y. Challenges of convalescent plasma therapy on COVID-19. J Clin Virol 2020; 127:104358. https://doi.org/10.1016/j.jcv.2020.104358

[80] Alzoughool F, Alanagreh L. Coronavirus drugs: using plasma from recovered patients as a treatment for COVID-19. Int J Risk Saf Med 2020; 31(2):47-51. https://doi.org/10.3233/JRS-201017

[81] Seghatchian J, Lanza F. Convalescent plasma, an apheresis research project targeting and motivating the fully recovered COVID 19 patients: a rousing message of clinical benefit to both donors and recipients alike. Transfus Apher Sci 2020; 59(3):102794. https://doi.org/10.1016/j.transci.2020.102794

[82] FDA. Coronavirus (COVID-19) Update: FDA Issues Emergency Use Authorization for Potential COVID-19 Treatment. 2020. Available from: https://www.fda.gov/news-events/press-announcements/coronavirus-covid-19update-fda-issues-emergency-use-authorization-potential-covid-19-treatment. [Accessed June 22, 2020]. 
[83] FDA. Fact Sheet for Health Care Providers Emergency Use Authorization (EUA) of Remdesivir (GS-5734,TM). 2020. Available from: https://www.fda.gov/media/137566/download. [Accessed June 22, 2020].

[84] Mulangu S, Dodd LE, Davey RT Jr, Tshiani Mbaya O, Proschan M, Mukadi D, et al. A randomized, controlled trial of Ebola virus disease therapeutics. N Engl J Med 2019; 381(24):2293-2303. https://doi.org/10.1056/NEJMoa1910993

[85] Cennimo DJ, Bergman SJ, Olsen KM. Coronavirus Disease 2019 (COVID-19) Treatment \& Management. Drugs \& Diseases, Infectious Diseases, Medscape. 2020. Available from: https://emedicine.medscape.com/article/2500114treatment\#d 10. [Accessed June 22, 2020].

[86] Sheahan TP, Sims AC, Graham RL, Menachery VD, Gralinski LE, Case JB, et al. Broad-spectrum antiviral GS-5734 inhibits both epidemic and zoonotic coronaviruses. Sci Transl Med 2017; 9(396): eaal3653. https://doi.org/10.1126/scitranslmed. aal3653

[87] Agostini ML, Andres EL, Sims AC, Graham RL, Sheahan TP, Lu X, et al. Coronavirus Susceptibility to the antiviral remdesivir (GS-5734) is mediated by the viral polymerase and the proofreading exoribonuclease. mBio 2018; 9(2):e0022 1-18. https://doi.org/10.1128/mBio.00221-18

[88] Chan KW, Wong VT, Tang SCW. COVID-19: an update on the epidemiological, clinical, preventive, and therapeutic evidence and guidelines of integrative Chinese-Western medicine for the management of 2019 novel coronavirus disease. Am J Chin Med 2020; 48(3):737-762. https://doi.org/10.1142/So192415X20500378

[89] Dong L, Hu S, Gao J. Discovering drugs to treat coronavirus disease 2019 (COVID-19). Drug Discov Ther 2020; 14(1):58-60. https://doi.org/10.5582/ddt.2020.01012

[90] Singh AK, Singh A, Singh R, Misra A. Remdesivir in COVID-19: a critical review of pharmacology, pre-clinical and clinical studies. Diabetes Metab Syndr 2020; 14(4):641-8. https://doi.org/10.1016/j.dsx.2020.05.018

[91] Wang Y, Zhang D, Du G, Du R, Zhao J, Jin Y, et al. Remdesivir in adults with severe COVID-19: a randomized, double-blind, placebo-controlled, multicenter trial. Lancet 2020; 395(10236):1569-78. https://doi.org/10.1016/So140-6736(20)31022-9

[92] Wang Y, Zhou F, Zhang D, Zhao J, Du R, Hu Y, et al. Evaluation of the efficacy and safety of intravenous remdesivir in adult patients with severe COVID-19: study protocol for a phase 3 randomized, double-blind, placebo-controlled, multicenter trial. Trials 2020; 21(1):422. https://doi.org/10.1186/s13063-020-04352-9

[93] Yousefifard M, Zali A, Mohamed Ali K, Madani Neishaboori A, Zarghi A, Hosseini M, et al. Antiviral therapy in management of COVID-19: a systematic review on current evidence. Arch Acad Emerg Med 2020; 8(1):e45.

[94] World Health Organization. Clinical management of severe acute respiratory infection when COVID-19 is suspected: interim guidance. 2020. WHO reference number: WHO/2019-nCoV/clinical/2020.5. This work is available under the CC BY-NC-SA 3.0 IGO Licence. Available from: https://www.who.int/publications-detail/clinical-managementof-severe-acute-respiratory-infection-when-novel-coronavirus-(ncov)-infection-is-suspected. [Accessed June 23, 2020].

[95] Kakodkar P, Kaka N, Baig MN. A comprehensive literature review on the clinical presentation and management of the pandemic coronavirus disease 2019 (COVID-19). Cureus 2020; 12(4):e7560. https://doi.org/10.7759/cureus.7560

[96] Sanders JM, Monogue ML, Jodlowski TZ, Cutrell JB. Pharmacologic treatments for coronavirus disease 2019 (COVID-19): a review. JAMA 2020; 10.1001/jama.2020.6019. https://doi.org/10.1001/jama.2020.6019

[97] Russell CD, Millar JE, Baillie JK. Clinical evidence does not support corticosteroid treatment for 2019-nCoV lung injury. Lancet 2020; 395(10223):473-5. https://doi.org/10.1016/S0140-6736(20)30317-2

[98] Stockman LJ, Bellamy R, Garner P. SARS: systematic review of treatment effects. PLoS Med 2006; 3(9):e343. https://doi.org/10.1371/journal.pmed.0030343

[99] Arabi YM, Mandourah Y, Al-Hameed F, Sindi AA, Almekhlafi GA, Hussein MA, et al. Corticosteroid therapy for critically ill patients with Middle East Respiratory Syndrome. Am J Respir Crit Care Med 2018; 197(6):757-67. https://doi.org/10.1164/rccm.201706-1172OC

[100] Ni YN, Chen G, Sun J, Liang BM, Liang ZA. The effect of corticosteroids on mortality of patients with influenza pneumonia: a systematic review and meta-analysis. Crit Care 2019; 23(1):99. https://doi.org/10.1186/s13054-0192395-8

[101] Haque M, Islam T, Rahman NAA, McKimm J, Abdullah A, Dhingra S. Strengthening primary health-care services to help prevent and control long-term (Chronic) non-communicable diseases in low- and middle-income countries. Risk Manag Healthc Policy 2020; 13:409-26. https://doi.org/10.2 147/RMHP.S239074

[102] Demaio AR, Kragelund Nielsen K, Pinkowski Tersbøl B, Kallestrup P, Meyrowitsch DW. Primary health care: a strategic framework for the prevention and control of chronic non-communicable disease. Glob Health Action 2014; 7:24504. https://doi.org/10.3402/gha.v7.24504

[103] Holmes KK, Bertozzi S, Bloom BR, Jha P, Gelband H, DeMaria LM, et al. Major Infectious Diseases: Key Messages from Disease Control Priorities, Third Edition. In: Holmes KK, Bertozzi S, Bloom BR, Jha P (Editors). Major Infectious Diseases. 3rd ed. Washington: The International Bank for Reconstruction and Development / The World Bank; 2017. Chapter 1. Available from: https://www.ncbi.nlm.nih.gov/books/NBK525197/ doi: 10.1596/9781-4648-0524-O_ch1. [Accessed June 23, 2020]. 
[104] Hashimoto K, Zúniga C, Nakamura J, Hanada K. Integrating an infectious disease program into the primary health care service: a retrospective analysis of Chagas disease community-based surveillance in Honduras. BMC Health Serv Res 2015; 15:116. https://doi.org/10.1186/s12913-015-0785-4

[105] Haque M. Combating COVID-19: a coordinated efforts of healthcare providers and policy makers with global participation are needed to achieve the desired goal. Bang J Med Sci 2020; 19:1-5. https://doi.org/10.3329/bjms.v19io.47610

[106] Vlassoff C, Tanner M, Weiss M, Rao S. Putting people first: a primary health care success in rural India. Indian J Community Med 2010; 35(2):326-30. https://doi.org/10.4103/0970-0218.66896

[107] Perry HB, Rohde J. The Jamkhed comprehensive rural health project and the Alma-Ata vision of primary health care. Am J Public Health 2019; 109(5):699-704. https://doi.org/10.2 105/AJPH.2019.304968 